\title{
Attitudes toward Cervical Cancer and Screening among Married Women Attending Outpatient Clinics at Maternity Hospitals in Baghdad City
}

\author{
Dr. Rabea Mohsen Ali, $\mathrm{PhD}^{1}$, Fatima Fadel Benyian, BSc. ${ }^{2}$ \\ ${ }^{1}$ Professor, Maternal and Neonatal Nursing Department, College of Nursing, University of Baghdad) \\ ${ }^{2}$ Maternal and Neonatal Nursing Department, College of Nursing, University of Baghdad)
}

\begin{abstract}
Cervical cancer is the most common cause of cancer deaths among women worldwide. However, it is a disease that can be prevented and cured. Developed countries have reported a significant reduction in the incidence rate of cervical cancer due to intensive screening programs. The Papanicolaou smear is plays an important role in reducing both the morbidity and mortality rate of cervical cancer .

Objective: To assess women attitude toward cervical cancer and screening and find out the association between women's attitude and their some study variables.

Methods: A cross sectional study was conducted between October 2016 and February 2017 at maternity hospitals in Baghdad city. data was collected through interview and self administered questionnaire which used to gather information from (400) women. Data are analyzed through the use of SPSS version 20.

Results: This study shows that majority of respondents (94\%) had positive attitudes toward cervical cancer and screening and only (11\%) of them have ever been screened with once Pap smear test. there was no statistical significant relationships between women's attitudes and socio demographic variables.

Conclusion: This study shown despite there are positive attitude toward cervical cancer and screening among study sample but their uptake of Pap smear was poor.

Recommendation: Women should be inform about their susceptibility to cervical cancer and encouraging them to do regular Pap smear test that detect precancerous lesion which prevent cervical cancer through early treatment of precancerous lesion.
\end{abstract}

Keywords: Attitudes, Cervical Cancer, Screening, Pap smear

\section{Introduction}

Cervical cancer is one of the leading causes of gynaecological cancer death of women in developing countries, but cervical cancer is a disease that can be prevented and cured. Early detection of the disease has reduced mortality and morbidity of the world. Papanicolaou (Pap) smear is an effective and affordable test for the detection of cellular changes in the cervix ${ }^{[1]}$.

Yoshino,et. al. stated that because of cervical cancer has few self reported symptoms, progression to invasive cancer is slow, early detection of precancerous lesions through screening is important for prevention. It is universally recognized that the prevalence of cervical cancer screening as a secondary prevention effectively reduce the incidence and mortality of cervical cancer ${ }^{[2]}$.

Developed countries have succeeded in controlling the incidence of cervical cancer, while the developing countries have failed miserably in this regard. The success of developed countries largely attributed to the widespread and systematic use of Pap smear ${ }^{[3]}$.

It is easy to understand that prevention and early detection plays a vital role. However, in order to implement preventive tools, women must be aware of the seriousness of the cervical cancer. Therefore, there is a need to obtain accurate data on the current knowledge of women about cervical cancer. The aim of all these efforts in launching campaigns that would encourage the human Papilloma virus (HPV) vaccination and cytological examination ${ }^{[4]}$.

Several reasons have been suggested for the little compliance, including insufficient knowledge toward the benefits of prevention and early detection, negative attitudes on electiveness preventive measures for cervical cancer, and limited access to services related to costs, and convenience ${ }^{[5]}$.

\section{Methods}

Cross-sectional descriptive analytic study design was conducted among women attending maternity hospitals outpatient clinics to identify their attitudes regarding cervical cancer and screening. The study was performed between October 2016 and February 2017 at maternity hospitals in Baghdad city. Non probability (purposive sample) used to collect the data from (400) married women who attained outpatient clinics in maternity hospitals. A questionnaire constructed about attitudes concerning cervical cancer and screening 
Attitudes Toward Cervical Cancer And Screening Among Married Women Attending Outpatient...

assessment tool were designed and prepared by the researchers. A pilot study conducted in order to determine the reliability of the questionnaire in a sample of (20) women who excluded from the study sample $(\mathrm{r} 1=0.96)$. Content validity was determined through a panel of (17) experts their experience mean and SD was 28.82 $\bar{\mp}$ 7.5. The data was collected after obtaining the agreement from women to participant in this study. The study instrument was consisted of five main parts which include: Socio demographic characteristics, reproductive variable, clinical variable, and women's attitudes toward cervical cancer and screening assessment tool consisted of (15) items. Data are analyzed through the use of SPSS (Statistical Process for Social Sciences) version 20

\section{Results}

Table (1) Women's Demographic Characteristics $(\mathrm{n}=400)$

\begin{tabular}{|c|c|c|}
\hline Socio Demographic Characteristics & $\mathbf{F}$ & $\%$ \\
\hline \multicolumn{3}{|l|}{ Age / years } \\
\hline$<20$ & 41 & 10.3 \\
\hline $20-29$ & 175 & 43.8 \\
\hline 30-39 & 118 & 29.5 \\
\hline $40-49$ & 49 & 12.3 \\
\hline $50-59$ & 17 & 4.3 \\
\hline Mean $=29.7625$ & & \\
\hline \multicolumn{3}{|l|}{ Marital Status } \\
\hline Married & 380 & 95.0 \\
\hline Divorced & 4 & 1.0 \\
\hline Separated & 12 & 3.0 \\
\hline Widow & 4 & $\mathbf{1 . 0}$ \\
\hline \multicolumn{3}{|l|}{ Age at marriage / years } \\
\hline $11-15$ & 68 & $\mathbf{1 7 . 0}$ \\
\hline 16-20 & 178 & 44.5 \\
\hline 21-25 & 97 & 24.3 \\
\hline $26-30$ & 43 & 10.8 \\
\hline (31 $\square)$ & 14 & 3.5 \\
\hline Mean $=19.9700 \quad \mathrm{SD}=\mathbf{5 . 0 4 2 0 9}$ & & \\
\hline \multicolumn{3}{|l|}{ Duration of marriage/ years } \\
\hline $1-9$ & 243 & 60.8 \\
\hline 10-19 & 93 & 23.3 \\
\hline $20-29$ & 43 & 10.8 \\
\hline 30-39 & 19 & 4.8 \\
\hline $40-49$ & 2 & .5 \\
\hline Mean $=9.8200$ & & \\
\hline \multicolumn{3}{|l|}{ Educational level } \\
\hline Not read & 37 & 9.3 \\
\hline Read and write & 45 & 11.3 \\
\hline Primary school & 118 & 29.5 \\
\hline Intermediate school & 83 & 20.8 \\
\hline secondary School & 46 & 11.5 \\
\hline Institute graduate & 25 & 6.3 \\
\hline College graduate & 43 & 10.8 \\
\hline Master and higher degree & 3 & .8 \\
\hline \multicolumn{3}{|l|}{ Occupation Status } \\
\hline Student & 13 & 3.3 \\
\hline Governmental employee & 62 & 15.5 \\
\hline Self-employed & 2 & .5 \\
\hline Retired & 3 & .8 \\
\hline Housewife & 320 & 80.0 \\
\hline \multicolumn{3}{|l|}{ Residence } \\
\hline Rural & 3 & .8 \\
\hline Urban & 397 & 99.3 \\
\hline \multicolumn{3}{|l|}{ Monthly income } \\
\hline Sufficient & 125 & 31.3 \\
\hline Mostly sufficient & 179 & 44.8 \\
\hline Insufficient & 96 & 24.0 \\
\hline \multicolumn{3}{|l|}{ Smoking } \\
\hline yes & 6 & 1.5 \\
\hline No & 394 & 98.5 \\
\hline
\end{tabular}

Table (1) results shows that the highest percentage (43.8\%) of participants was at age group (20-29) years, more than one third (44.5\%) married before (16-20) years, nearly two third of them $(60.8 \%)$ married for (1-9) years, more than quarter of them (29.5\%) had primary school graduation, the majority of women $(80 \%)$ 
Attitudes Toward Cervical Cancer And Screening Among Married Women Attending Outpatient...

were housewives, nearly half of the study sample $(44.8 \%)$ were mostly sufficient income, and the majority of them $(98.5 \%)$ weren't smoker women.

Table (2) Women's Reproductive Characteristics ( $\mathrm{n}=400)$

\begin{tabular}{|c|c|c|}
\hline Reproductive Characteristics & $\mathbf{F}$ & $\%$ \\
\hline \multicolumn{3}{|l|}{ Gravidity } \\
\hline Nulligravida & 19 & 4.8 \\
\hline $1-2$ & 149 & 37.3 \\
\hline $3-4$ & 113 & 28.3 \\
\hline$(5 \square)$ & 119 & 29.8 \\
\hline \multicolumn{3}{|l|}{ Parity } \\
\hline Nullipara & 89 & 22.3 \\
\hline $1-2$ & 141 & 35.3 \\
\hline $3-4$ & 99 & 24.8 \\
\hline$(5 \square)$ & 71 & $\mathbf{1 7 . 8}$ \\
\hline \multicolumn{3}{|l|}{ Alive children } \\
\hline None & 90 & 22.5 \\
\hline $1-2$ & 142 & 35.5 \\
\hline $3-4$ & 98 & 24.5 \\
\hline$(5 \square)$ & 70 & $\mathbf{1 7 . 5}$ \\
\hline \multicolumn{3}{|l|}{ Abortion } \\
\hline None & 269 & 67.3 \\
\hline $1-2$ & 106 & 26.5 \\
\hline 3-4 & 24 & 6.0 \\
\hline$(5 \square)$ & 1 & .3 \\
\hline \multicolumn{3}{|l|}{ Using family planning methods } \\
\hline No & 237 & 59.3 \\
\hline Yes & 163 & 40.7 \\
\hline \multicolumn{3}{|l|}{ Types of family planning } \\
\hline None & 237 & 59.3 \\
\hline Condoms & 15 & 3.8 \\
\hline Pills & 74 & 18.5 \\
\hline Injection & 19 & 4.8 \\
\hline Intrauterine device & 55 & 13.8 \\
\hline
\end{tabular}

The results shows in table (2) that more than one third (37.3\%) of participants had (1-2) pregnancy, (12) parity, (1-2) alive children, more than two third (67.3\%) hadn't abortion, more than half (59.3\%) didn't use contraception, and more than one third $(40.7 \%)$ were use contraception higher percentage of them $(18.5 \%)$ were use pills method.

Table (3) Women's Clinical Variables $(\mathrm{n}=400)$

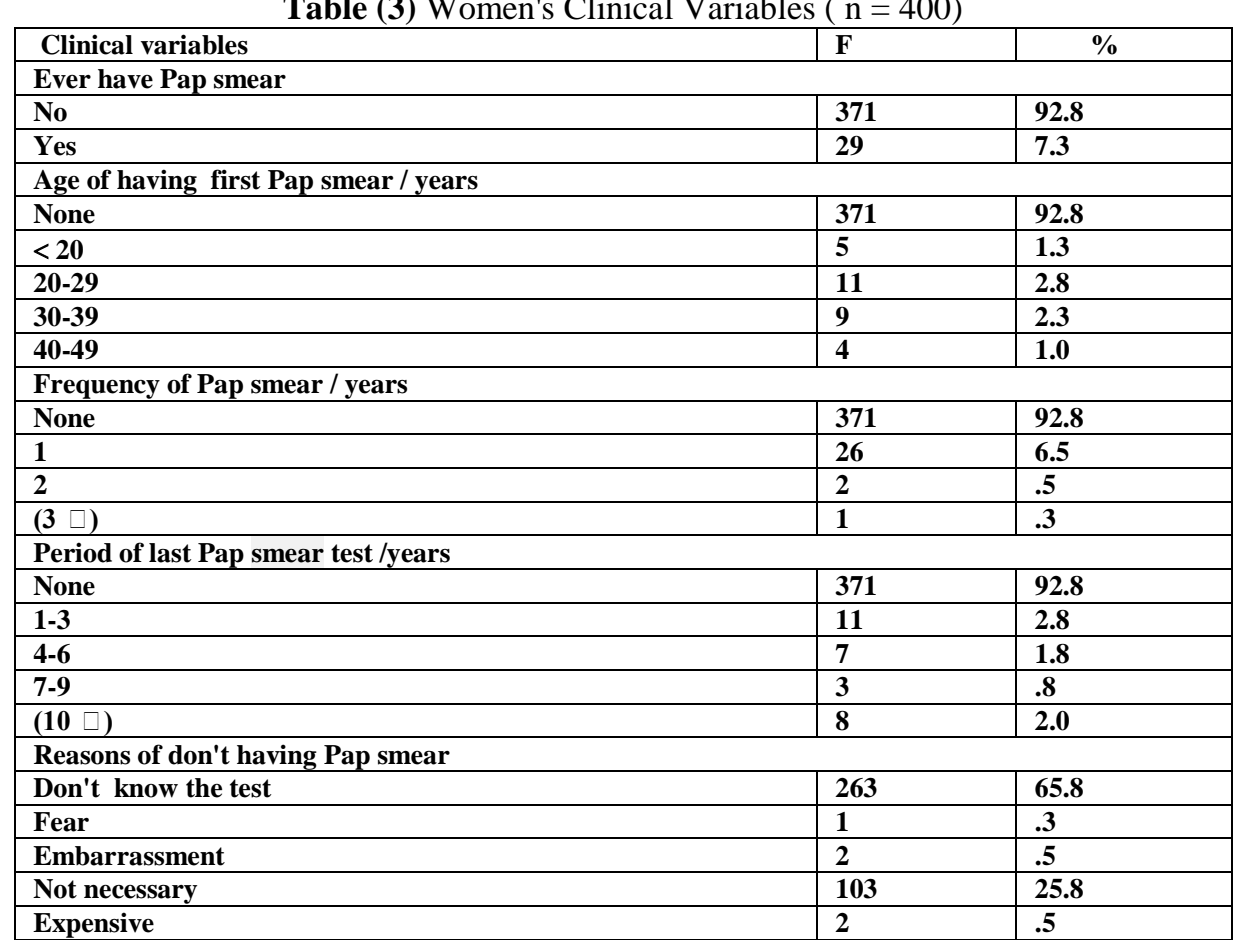


Attitudes Toward Cervical Cancer And Screening Among Married Women Attending Outpatient...

\begin{tabular}{|l|l|l|}
\hline Have Pap smear & 29 & 7.3 \\
\hline Family history of cervical cancer & 10 & 2.5 \\
\hline Yes & 390 & 97.5 \\
\hline No & 390 & 97.5 \\
\hline The relation of relative suffered from cervical cancer & 3 & .8 \\
\hline None & 1 & .3 \\
\hline Mother & 6 & 1.5 \\
\hline Sister & 6 \\
\hline Aunt &
\end{tabular}

The results shows in table (3) that the most (92.8\%) of the study sample didn't have Pap smear, while only (7.3\%) have once Pap smear before (1-3) years, their age of first Pap smear test were between (20-29) years, and the reason of those didn't have Pap smear test were "don't know the test". The majority of them $(97.5 \%)$ hadn't family history of cervical cancer.

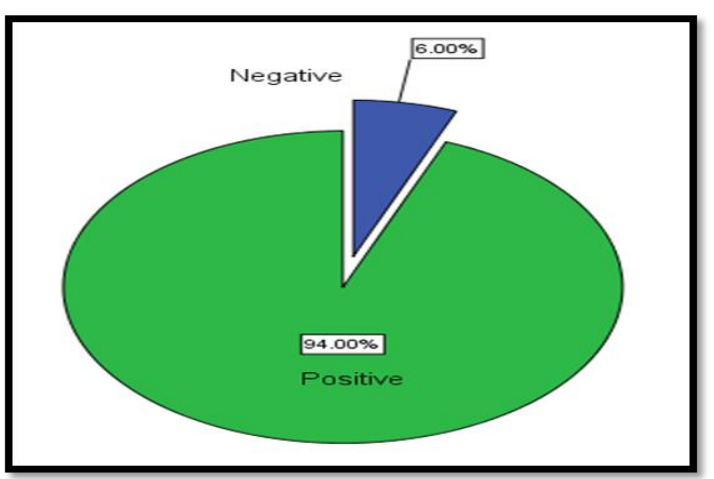

Figure (1) women's attitudes toward cervical cancer and screening

Table (4.) Association between women's attitudes and some study variables ( $n=400)$

\begin{tabular}{|c|c|c|c|c|c|c|c|c|c|}
\hline \multirow{2}{*}{\multicolumn{2}{|c|}{ Socio Demographic variables }} & \multicolumn{4}{|c|}{ Attitudes } & \multirow{3}{*}{\multicolumn{3}{|c|}{ Chi square statistics }} & \multirow[t]{4}{*}{ Sig. } \\
\hline & & \multirow{2}{*}{\multicolumn{2}{|c|}{ Positive }} & \multirow{2}{*}{\multicolumn{2}{|c|}{ Negative }} & & & & \\
\hline & & & & & & & & & \\
\hline \multirow{6}{*}{ Age / years } & & & & & 70 & \multirow{6}{*}{2.303} & \multirow{6}{*}{4} & \multirow{6}{*}{.680} & \\
\hline & $<20$ & 39 & 95.1 & 2 & 4.9 & & & & \multirow[t]{5}{*}{ NS. } \\
\hline & $20-29$ & 161 & 92.0 & 14 & 8.0 & & & & \\
\hline & 30-39 & 113 & 95.8 & 5 & 4.2 & & & & \\
\hline & $40-49$ & 47 & 95.9 & 2 & 4.1 & & & & \\
\hline & $50-59$ & 16 & 94.1 & 1 & 5.9 & & & & \\
\hline \multirow{5}{*}{$\begin{array}{l}\text { Duration of } \\
\text { marriage / years }\end{array}$} & $1-9$ & 225 & 92.6 & 18 & 7.4 & \multirow[t]{5}{*}{2.809} & \multirow{5}{*}{4} & \multirow[t]{5}{*}{.590} & \multirow[t]{5}{*}{ NS. } \\
\hline & 10-19 & 89 & 95.7 & 4 & 4.3 & & & & \\
\hline & $20-29$ & 41 & 95.3 & 2 & 4.7 & & & & \\
\hline & 30-39 & 19 & 100 & $\mathbf{0}$ & $\mathbf{0 . 0}$ & & & & \\
\hline & $40-49$ & 2 & 100 & $\mathbf{0}$ & $\mathbf{0 . 0}$ & & & & \\
\hline \multirow[t]{8}{*}{ Educational level } & Not read & 35 & 94.6 & 2 & 5.4 & \multirow{8}{*}{6.010} & \multirow{8}{*}{7} & \multirow[t]{8}{*}{.539} & \multirow[t]{8}{*}{ NS. } \\
\hline & Read and write & 40 & 88.9 & 5 & 11.1 & & & & \\
\hline & Primary school & 115 & 97.5 & 3 & 2.5 & & & & \\
\hline & Intermediate school & 76 & 91.6 & 7 & 8.4 & & & & \\
\hline & secondary School & 43 & 93.5 & 3 & 6.5 & & & & \\
\hline & Institute graduate & 23 & 92.0 & 2 & 8.0 & & & & \\
\hline & College graduate & 41 & 95.3 & 2 & 4.7 & & & & \\
\hline & Master and higher & 3 & 100 & $\mathbf{0}$ & $\mathbf{0 . 0}$ & & & & \\
\hline \multirow[t]{4}{*}{ Parity } & Nullipara & 81 & 91.0 & 8 & 9.0 & \multirow[t]{4}{*}{2.075} & \multirow[t]{4}{*}{3} & \multirow[t]{4}{*}{.557} & \multirow[t]{4}{*}{ NS. } \\
\hline & $1-2$ & 134 & 95.0 & 7 & 5.0 & & & & \\
\hline & $3-4$ & 93 & 93.9 & 6 & 6.1 & & & & \\
\hline & $(5 \square)$ & 68 & 95.8 & 3 & 4.2 & & & & \\
\hline \multirow[t]{4}{*}{ Abortion } & None & 255 & 94.8 & 14 & 5.2 & \multirow[t]{4}{*}{4.114} & & .249 & NS. \\
\hline & $1-2$ & 96 & 90.6 & 10 & 9.4 & & 3 & & \\
\hline & $3-4$ & 24 & 100 & $\mathbf{0}$ & 0.0 & & & & \\
\hline & $(5 \square)$ & 1 & 100 & $\mathbf{0}$ & 0.0 & & & & \\
\hline Contraception & No & 223 & 94.1 & 14 & 5.9 & .009 & & .925 & NS. \\
\hline & Yes & 153 & 93.9 & 10 & 6.1 & & & & \\
\hline
\end{tabular}

( df) degree of freedom, (Sig) significant Probability value (P < 0.05), $\quad$ (NS) Non Significant.

Table (4) results shows that there was no statistical significant differences between women's attitudes and study variables. 


\section{Discussion}

At personal level, the decision by an asymptomatic women to undergo a timely preventive or screening test depends on whether that women believes in the feasibility and usefulness of the screening, perceived susceptibility, severity, barriers, benefits of action, and whether there is clear understanding of the problem against which the test is directed ${ }^{[6]}$.

This study looked at the respondents attitude toward cervical cancer and screening the results shows that the majority of study sample $(94 \%)$ had positive attitude toward cervical cancer and screening. The higher percentage of them (83\%) like to participate in a national cervical cancer screening program. The higher percentage of respondents $(81.3 \%)$ like to know more knowledge about cervical cancer. The higher percentage of respondents $(80.5 \%)$ like to receive HPV vaccine, these results is consistent with AL-Sairafi \& Mohamed found that about one third of respondents $(30.6 \%)$ had adequate attitude towards Pap smear test and the majority of participants liked to know more about Pap smear test and like to participate in a national cervical cancer screening program if the ministry of health initiates program ${ }^{[1]}$. Donati found that more than two third of the respondents $(72 \%)$ indicated that they would accept being vaccinated against HPV infection ${ }^{[7]}$. Wong showed that more than two third of his study population $(65 \%)$ professed an intention to receive the HPV vaccine ${ }^{[8]}$.

Regarding Pap smear test the most of the study sample (92.8\%) didn't have Pap smear, while only (7.2\%) have Pap smear, these results is consistent with Shrestha who stated that the uptake of Pap smear test was only $(10.5 \%)$ in their respondents ${ }^{[9]}$. Amarin mentioned that most of study population $(85.7 \%)$ had never received a Pap smear and only $(14.3 \%)$ had Pap smear test ${ }^{[10]}$.

Regarding reason of didn't have Pap smear test the higher percentage of participants $(65.8 \%)$ were "didn't know the test", also approximately quarter of study sample (25.8\%) were answered with "not necessary", these results is consistent with Bansal who demonstrated that more than two third $(65 \%)$ responded that they were unaware of the screening test for cervical cancer ${ }^{[11]}$. John showed that one third of the study population $(30.7 \%)$ barrier was the lack of knowledge ${ }^{[12]}$. Amarin reported that the major barriers to Pap smear screening include inadequate knowledge about the test ${ }^{[10]}$. Sait stated that the main reason for not having a Pap smear was the lack of awareness ${ }^{[13]}$.

Regarding association between women's attitudes and study variables this study shows that there are no statistical significant differences between women's attitudes and socio demographic variables, these result is consistent with Cerigo who found that there are no statistically significant associations were found when responses to questionnaire items on women's experiences, attitudes and beliefs about cervical cancer ${ }^{[14]}$.

\section{Conclusion}

This study revealed that women's attitude was generally positive as most of them showed a positive attitude towards cervical cancer and screening, but they had low rate of screening for premalignant cervical lesions with Pap smear test. This attitude however did not improve practice and this could have been contributed by barriers that were they don't know the test and though it is not necessary.

\section{Recommendation}

- Women should be inform about their susceptibility to cervical cancer and encouraging them to do regular Pap smear test that detect precancerous lesion which prevent cervical cancer through early treatment of precancerous lesion.

- Increase cervical cancer screening rates through health education and gynecologist, health care professionals recommendation for Pap smear test to all married women every 3 years.

\section{References}

[1]. AL-Sairafi, M.; Mohamed, F.: Knowledge, Attitudes, and Practice Related to Cervical Cancer Screening among Kuwaiti Women, Med Princ, 18, 2009, 35-42.

[2]. Yoshino,Y.; Ohta, H.; Kawashima,M.; Wada,K.; Shimizu,M.,et.al.: The knowledge of cervical cancer and screening adherence among nurses at a university-affiliated hospital in Japan, Kitasato Med J,42, 2012, 6-14.

[3]. Uysal ,A.; Birsel, A.: Knowledge about Cervical Cancer Risk Factors and Pap Testing Behaviour among Turkish Women, Asian Pacific J Cancer Prev,2009, Vol. 10, 345-350.

[4]. Jaglarz, K.; Tomaszewski, K.; Kamzol, W.; Puskulluoglu, M.; Krzemieniecki,K.: Creating and field-testing the questionnaire for the assessment of knowledge about cervical cancer and its prevention among schoolgirls and female students, J Gynecol Oncol, 2013, Vol. 25 (2), 81-89

[5]. Pavia,M.; Ricciardi,G.; Bianco,A.; Pantisano,P.; Langiano,E.: Breast and cervical cancer screening: Knowledge, attitudes and behavior among schoolteachers in Italy, European Journal of Epidemiology,15, 1999, 307-311.

[6]. Gichangi, P. ; Estambale, B. ; Bwayo, J. ; Rogo, K.; Ojwang, S. ; et.al.: Knowledge and practice about cervical cancer and Pap smear testing among patients at Kenyatta National Hospital, Nairobi Kenya, Int J Gynecol Cancer, 13, 2003,827 -833.

[7]. Donatia,S.; Giambib,C.; Declichb,S.; Salmasoc,S.; Filia,A.: Knowledge, attitude and practice in primary and secondary cervical cancer prevention among young adult Italian women, Vaccine, 30, 2012, 2075-2082.

[8]. Wong, L.: Knowledge and Attitudes About HPV Infection, HPV Vaccination, and Cervical Cancer Among Rural Southeast Asian Women, Int.J. Behav. Med., 2010. 
[9]. Shrestha, S.; Saha,R.; Tripathi, N.: Knowledge, Attitude and Practice regarding Cervical Cancer Screening Amongst Women visiting Tertiary Centre in Kathmandu, Nepal, NJMS, 2 (2), 2013, 85-89.

[10]. Amarin, Z.; Badria,L.; Obeidat, B.: Attitudes and beliefs about cervical smear testing in ever-married Jordanian women, Eastern Mediterranean Health Journal, 14 (2), 2008, 389-395.

[11]. Bansal, A.; Pakhare,A.; Kapoor,N.; Mehrotra, R.; Kokane,A.: Knowledge, attitude, and practices related to cervical cancer among adult women: A hospital-based cross-sectional study, Journal of Natural Science, Biology and Medicine, 6 (2), 2015, 324-327.

[12]. John,J.: The Knowledge, Attitude, Practice And Perceived Barriers Towards Screening For Premalignant Cervical Lesions Among Women Aged 18years And Above, In Songea Urban, Ruvuma, Published dissertation, Muhimbili University of Health and Allied Sciences, (2011).

[13]. Sait,K.H.: Attitudes, knowledge, and practices in relation to cervical cancer and its screening among women in Saudi Arabia, Saudi Med J, 30 (9), 2009, 1208-1211.

[14]. Cerigo,H.; Macdonald,M.; Franco1,E.; Brassard,P.: Inuit women's attitudes and experiences towards cervical cancer and prevention strategies in Nunavik, Quebec, Int J Circumpolar Health, 71, 2012, 1-8. 